\title{
赤露素的化学合成研究 (I)
}

\section{一一赤霰素 $\mathrm{GA}_{23}$ 甲酯的立体选择性合成*}

\author{
姜标潘 䤧 \\ (兰州大学应用有机化学实跲室)
}

\section{关锤词赤素 $\mathrm{GA}_{23}$ 甲䣲、合成}

赤霰素 (Gibberellins) 是一类重要的、具有多种生理活性的植物生长激素, 因在农业、植 物生理学、园艺学及医学等方面有着广泛用途, 从而引起化学家和植物生理学家的极大兴趣, 并对该类化合物进行了长期的深人研究 ${ }^{[1]}$.

自 1938 年首次分离出赤需酸 $\left(G_{3}\right)$ 的粗品以来, 迄今已有 50 年的研究历史 ${ }^{[2]}$, 但对该 类化合物的研究经久不衰, 目前仍是国外几个著名实验室的重点研究课题. 在赤毒素半合成 研究中, 以价廉、容易得到的赤霉酸 $\left(\mathrm{GA}_{3}\right)$ 为原料, 通过化学转化制备天然界稀少的其它赤 素是个活跃的研究课题, 但以往这方面的研究工作多局限于 $\mathrm{C}_{19}$ - 类赤電素之间的相互转

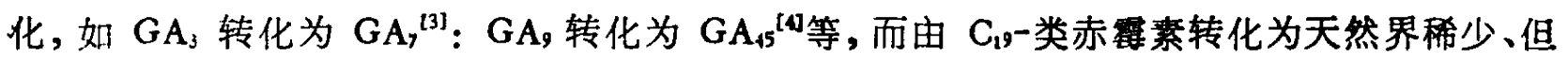
在生物合成研究中有重要意义的 $\mathrm{C}_{20}$ - 类赤霉素的研究却很少, 只是在近年来才有少量研究工 作报道, 如 Mander 等以赤霉酸 $\left(\mathrm{GA}_{3}\right)$ 为原料, 成功地合成了 $\mathrm{C}_{20}$ - 类的赤霉素 $\mathrm{GA}_{19}$ 及 $\mathrm{GA}_{36} 、 \mathrm{GA}_{37}$ 甲酯 ${ }^{[9]}$. 天然界稀少的 $\mathrm{C}_{20}$-类的另一个赤霉素 $\mathrm{GA}_{23}$ 的合成尚末见有报道. 该 化合物仅由日本学者 Fukui 等 1966 年从黄羽扇豆 (Lupinus luteus) 未成熟的果实中分离 得到过 ${ }^{161}$. 现本文简报以赤霉酸 $\mathrm{GA}_{3}$ 为原料, 立体选择性合成 $\mathrm{GA}_{23}$ 甲酯的结果, 具体合成 路线如下:

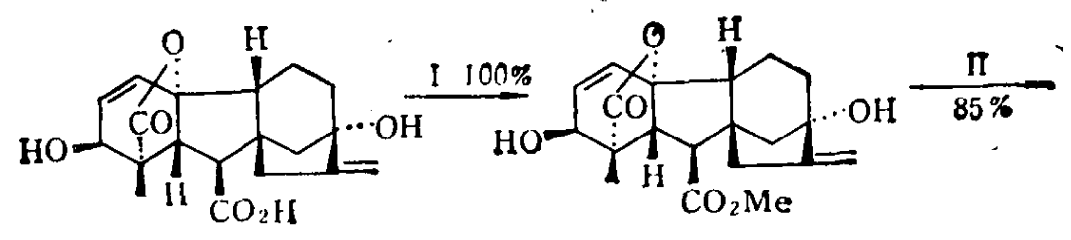

$\stackrel{2}{2}$

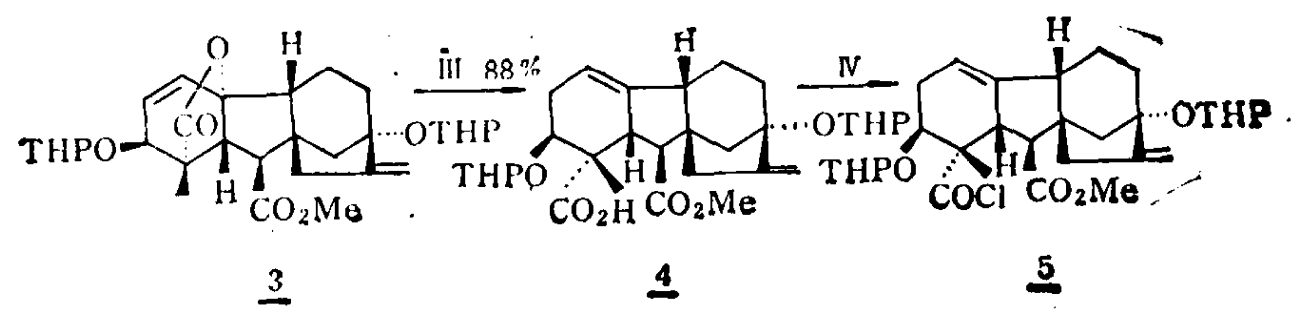

本文1983 年 7 月 13 日收到. 1988 年 9 月 20 日收到修改稆.

- 国家自然科学基金资助项目.

*通讯扶系人. 


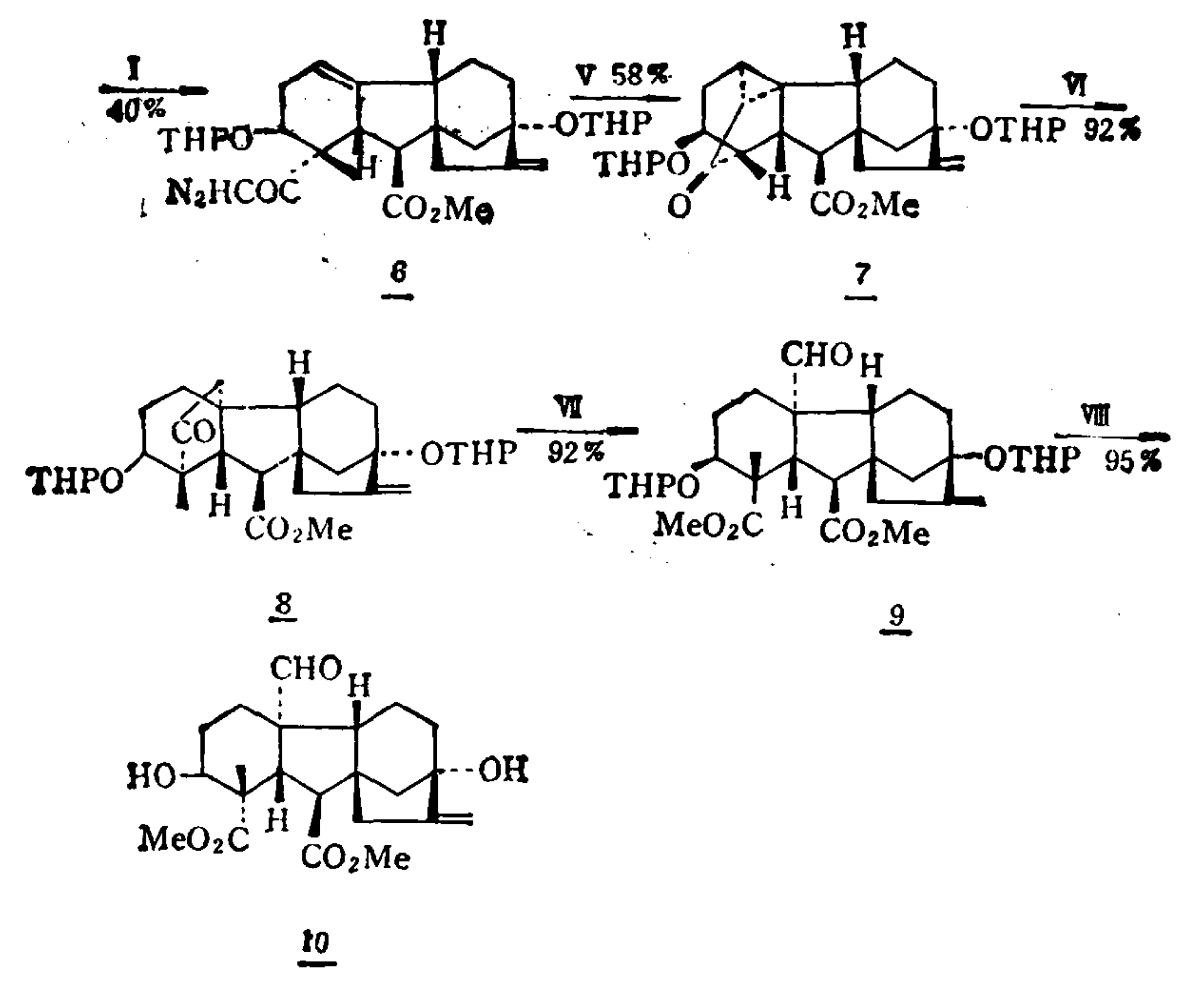

树: I. $\mathrm{CH}_{2} \mathrm{~N}_{2}$; II. DHP, P-TsOH; III. $\mathrm{NiCl}_{2}-\mathrm{NaBH}_{4}-\mathrm{MeOH}$; IV. (COCl);

V. Bronze Power-(Cylohexane: THF); VI. $\mathrm{Li} / \mathrm{liq}, \mathrm{NH}_{3} / \mathrm{t}$-BuOH;

VII. $\mathrm{N}_{2} \mathrm{H}-\left(\mathrm{DMF}\right.$ : THF). $-\mathrm{O}_{2}-\mathrm{CH}_{9}$; VIII. Trace TMSCl- $\left(\mathrm{CH}_{2} \mathrm{Cl}_{2}: \mathrm{MeOH}\right)$

各中间体的结构均经 IR、MS、 'HNMR 测试数据确证. 产物 10 的光谱数据如下（括号 内的数据为文献值 $\left.{ }^{[0]}\right)$ :

IR (shimadzu 440, 涂膜): $3500-3300(3500-3300) \mathrm{br}, \mathrm{cm}^{-1},-\mathrm{OH} ; 1720(1713)$ br. $\mathrm{cm}^{-1},-\mathrm{C}=\mathrm{O} ; 1660,895(1658,893), \mathrm{cm}^{-1}, \mathrm{C}=\mathrm{C}$.

EIMS (JMS-olu)m/e: $406(406)\left(\mathrm{M}^{+}\right)$.

'HNMR (varian XL-200, $\mathrm{CDCl}_{3}, \mathrm{TMS}$ 为内标). $\delta: 1.21(1.20),\left(\mathrm{S}, 3 \mathrm{H},-\mathrm{CH}_{3}\right)$; $1.82(2.05)(\mathrm{S}, 2 \mathrm{H},-\mathrm{OH}$, 重水交换后消失, 在 $\delta 4.7$ 处出现水蜂); $3.66,3.74(3.65,3.73)$ $\left(2 \mathrm{~S}, 2 \times 3 \mathrm{H}, 2 \times-\stackrel{\stackrel{O}{\|}}{\mathrm{C}}-\mathrm{OCH}_{3}\right) ; 4.12(4.11)(m, 1 \mathrm{H}, \underline{\mathrm{H}}-\underset{\mathrm{C}}{\mathrm{C}}-\mathrm{OH}), 4.95,5.18$ (4.9.3, 5.17) $\left(m, 2 \mathrm{H}, \mathrm{C}=\mathrm{CH}_{2}\right) ; 9.71(9.72)(\mathrm{S}, 1 \mathrm{H},-\mathrm{CHO})$.

致谢：本研究得到 L. N. Mander 教授及周维善教授的热情鼓励和支持, 谨致谢地。

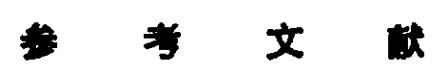

[1] Cathey, H. M. and Stuart, N. W., Annu. Rew. Plant Physical, 12(1961), 369.

[2] Yabuta, T. and Sumiki, Y., J. Agr. Chem. Soc. (Japan), 14(1938), 1526.

[ 3 ] MacMillian, J. et al., J. Chem. Reas(s), 1980, 289.

[4] Dolan, S. C., Holdup, W. et al., J. Chem. Soc., Pekin Trans., 1985, 651.

[ 5 ] (a) Robert, D. Mander, L. N. and Turner, J. V., Tetrahedron Letzers, 26(1985), 363

(b) Robert, D. et al., Tetrahedron Letters, 26(1985), 5725.

[6] Koshimizu, K., Fukui, H. et al., Tetrahedron Letters. 1966, 2459; 1968, 1143. 